\title{
Measuring supply chain performance in the healthcare industry
}

\author{
Karthikeyan Lenin \\ Bharathiar University 219, Pushpam colony, 3rd cross, Arulananda nagar extension, Thanjavur-613007. Tamilnadu, UAE
}

\section{Email address:}

karthik71@gmail.com

\section{To cite this article:}

Karthikeyan Lenin. Measuring Supply Chain Performance in the Healthcare Industry. Science Journal of Business and Management. Vol. 2, No. 5, 2014, pp. 136-142. doi: 10.11648/j.sjbm.20140205.14

\begin{abstract}
The fundamental success of supply chain management involves the effective coordination and integration of all the entities among the various supply chain partners-for example, suppliers, distributors, inbound and outbound transportation, third-party logistics companies, and information systems providers. Healthcare supply chain management differs from other application in term of key elements as it tends to be misalignment, high costs for healthcare providers and heavy dependence on third party. There are multitudes of factors to be considered so as to ensure on-time delivery, protection and product integrity from origin to destination. The objective of the article is to critically assess and investigate the supply chain activities of Al Zahrawi Medical, U.A.E and to identify and address the areas of weakness that may affect organizational performance. The findings suggested that optimizing the operations would help the company to achieve higher profits and have a competitive advantage.
\end{abstract}

Keywords: Supply Chain, Health care, Performance, SCOR

\section{Introduction}

In today's challenging business environment the organizations have started to realize that their success is highly dependent on their capacity to design and manage their supply chain management system in order to reap maximum benefits and to sustain competitive advantage in a fast-moving global world. In the present circumstances of accelerating globalization and the proliferation of multi-national companies the objectives of supply chain management is to improve quality of the goods \& services, to increase customer service/responsiveness, to reduce waste and non-value-added activities (i.e. cost reduction) including excess inventory, to improve supply chain communication (speed/timeliness, accuracy of information, information sharing), reduce cycle time (e.g. new product development, supply lead time) and the most important element i.e. the satisfaction of the ultimate customer (Kauffman, No date, p-1).

The fundamental success of supply chain management involves the effective coordination and integration of all the entities among the various supply chain partners-for example, suppliers, distributors, inbound and outbound transportation, third-party logistics companies, and information systems providers.
Due to the rapid advancement in medical technology and life sciences market, health care supply chain is under severe pressure. Healthcare supply chain management differs from other application in term of key elements as it tends to be misalignment, high costs for healthcare providers and heavy dependence on third party. There are multitudes of factors to be considered so as to ensure on-time delivery, protection and product integrity from origin to destination.

The objective of the article is to critically assess and investigate the supply chain activities of Al Zahrawi Medical, U.A.E and to identify and address the areas of weakness that may affect organizational performance. Based on the analysis the overall performance of the company will be assessed and this would help the management to identify potential supply chain problems and to take corrective actions and devise improvement strategies in order to improve their business performance. Possible solutions to optimize the chain would be concluded based on the findings. To make the analysis more effective the author included all the channel partners-suppliers (medical device manufacturers) distributor (Al Zahrawi Medical, U.A.E) and customers (government and private hospitals/laboratories) as the part of this study. Finally a SCOR (Supply Chain Operations Reference) Performance matrix will be designed to analyze the performance trend for areas under improvement and to 
compare with industry best practice performance.

\section{Review of Literature - Supply Chain Management for Medical Devices}

The healthcare industry has contributed significantly in both economic development and social welfare in modern economies. It is a highly competitive industry and it is heavily reliant on a vast and complex network of companies working to design, manufacture, deliver, and administer a wealth of health and medical related products and services. The management of health care has stimulated a great deal of attention of several researches and practitioners over the past two decades. The main challenge in the healthcare supply chain management is to achieve improved performance and service.

The healthcare supply chain shares a number of similarities with other chains, not only in terms of processes (e.g. procurement, warehousing, distribution), but also in terms of discerning customers and management structures (Walters and Rainbird, 2007,p-335). There are also considerable differences in the chain that are associated to the specific characteristics and requirements of the sector. In general, healthcare supply chains are very complex, fragmented, diverse, and dynamic. The main reason for this increasing level of complexity is due to the participation of multiple organizations, who are involved across the entire value chain and it requires key competencies.

It is essential to determine what needs to happen in the medical device industry to put the right material in the right place at the right time in the right quantity and receive a positive outcome from company, the hospital, patient, doctor, etc (Medina et al, 2014, p-1). According to a research study presented to the Medical Device Supply Chain Council in $2011,40-45 \%$ of the hospital operating expense is represented by supply chain and potential savings of 5-15\% of supply chain cost can be realized with better supply chain management strategies (Global Healthcare Exchange, 2011).

The healthcare supply chain generally consists of four main components: producers, purchasers, providers and patients (Medina et al, 2014, p-2). Smith et al presented the illustration in Figure 1 to represent the supply chain of the healthcare system.

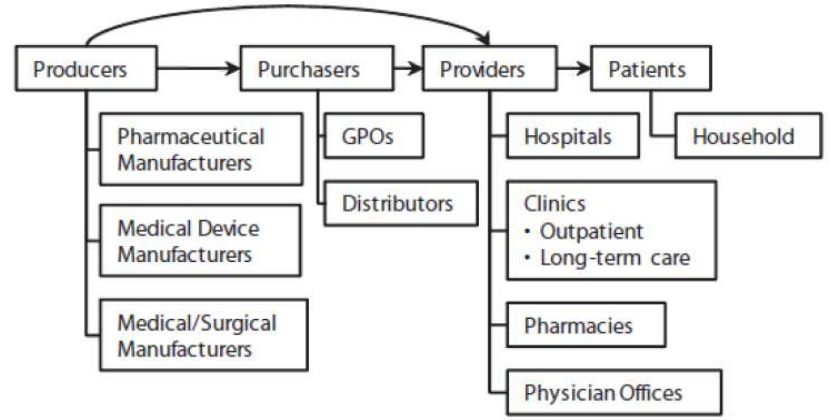

Fig 1. Healthcare systems supply chain (Source: Smith et al, 2012, p-4)
The Supply Chain Operations Reference-model (SCOR) is a process reference model that has been developed and endorsed by the Supply Chain Council as the cross-industry standard diagnostic tool for supply chain management. SCOR enables users to address, improve and communicate supply chain management practices within and between all interested parties.

The SCOR-model which is an integrated approach has been developed to describe the high level business activities associated with all phases of satisfying a customer's demand (Alfaro and Ceroni, 2011, p-259) By describing supply chains using these process building blocks, the model can be used to describe supply chains that are very simple or very complex using a common set of definitions. As a result, disparate industries can be linked to describe the depth and breadth of virtually any supply chain. The model has been able to successfully describe and provide a basis for supply chain improvement for global projects as well as site specific projects (ibid). The purpose of SCOR model is to define a company's current supply chain processes, quantify the performance of similar companies to establish targets to achieve "best in class" performance and identify practices and software solutions that will yield "best in class" performance.

According to Ling Lia et al the SCOR - model integrates the concept of business process re-making, setting up benchmarks, and process measurement into a cross functional framework ( $\mathrm{Li}$ et al, 2010,p-34). The model spans all product transactions from the main supplier's supplier to the customer's customer and spans all market interactions from demand forecasting to the order fulfillment. This model specifies five performance metrics in two categories: customer-facing metrics that include reliability, responsiveness and flexibility and the internal facing metrics that include costs and assets.

Though quality is not explicitly addressed in the performance metrics, reliability and responsiveness are quality indicators defined by quality gurus such as Deming (1981), Feigenbaum (1983) and Garvin (1988).

\begin{tabular}{|c|c|c|}
\hline Performance Attribute & Performance Attribute Definition & Level 1 Metric \\
\hline $\begin{array}{l}\text { Supply Chain } \\
\text { Reliability }\end{array}$ & $\begin{array}{l}\text { The performance of the supply chain in } \\
\text { delivering: the correct product, to the correct } \\
\text { place, at the correct time, in the correct } \\
\text { condition and packaging, in the correct } \\
\text { quantity, with the correct documentation, to the } \\
\text { correct customer. }\end{array}$ & Perfect Order Fuffillment \\
\hline $\begin{array}{l}\text { Supply Chain } \\
\text { Responsiveness }\end{array}$ & $\begin{array}{l}\text { The speed at which a supply chain provides } \\
\text { products to the customer. }\end{array}$ & Order Fulfillment Cycle Time \\
\hline \multirow{3}{*}{$\begin{array}{l}\text { Supply Chain } \\
\text { Flexibility }\end{array}$} & \multirow{3}{*}{$\begin{array}{l}\text { The agility of a supply chain in responding to } \\
\text { marketplace changes to gain or maintain } \\
\text { competifive advantage. }\end{array}$} & Upside Supply Chain Flexibility \\
\hline & & Upside Supply Chain Adaptability \\
\hline & & Downside Supply Chain Adaptability \\
\hline \multirow[t]{2}{*}{ Supply Chain Costs } & \multirow{2}{*}{$\begin{array}{l}\text { The costs associated with operating the supply } \\
\text { chain. }\end{array}$} & Supply Chain Management Cost \\
\hline & & Cost of Goods Sold \\
\hline \multirow{3}{*}{$\begin{array}{l}\text { Supply Chain Asset } \\
\text { Management }\end{array}$} & \multirow{3}{*}{$\begin{array}{l}\text { The effectiveness of an organization in } \\
\text { managing assets to support demand } \\
\text { satisfaction. This includes the management of } \\
\text { all assets: fixed and working capital. }\end{array}$} & Cash-10-Cash Cycle Time \\
\hline & & $\begin{array}{l}\text { Return on Supply Chain Fixed } \\
\text { Assets } \\
\end{array}$ \\
\hline & & Return on Working Capital \\
\hline
\end{tabular}

Fig 2. SCOR Performance Metrics (Source: Mathew alias Jerry, 2014, p-30) 


\section{Global Scenario of the Medical Device Industry}

The global medical device manufacturing industry is made up of more than 27,000 firms worldwide and employs about one million people. Traditionally this industry has a low level of industry concentration, with no one firm dominating (Ryder, 2013).

Small companies are widespread and they often specializes in developing niche technology strategies, while larger firms tries to seek strategic alliances with smaller firms to expand their business and new entrants or gain access to a particular technology or market. However unprecedented consolidation over the past five years has swept this industry and the number of companies has been considerably decreased. The emerging markets particularly China and Brazil are relatively new entrants in medical device manufacturers.

In 2011, the key business segments of the global medical device market were consumables (15\%), diagnostic apparatus (e.g., MRI and CT-scan) (27\%), patient aids such as hearing aids and pacemakers (12\%), orthopaedic products $(11 \%)$, dental products $(7 \%)$, and other medical equipment $(28 \%)$.

In order to compete effectively in this global economy these medical device companies are expected to realign their business structures such as emerging - market growth, health care reform and cost control. Anticipated changes include company restructuring as well as an increased reliance on strategic alliances and outsourcing for marketing, distribution, research and manufacturing activities.

\section{UAE Medical Device Industry - An Overview}

Healthcare has proven to be one of the UAE's most resilient sectors in the face of International economic woes and has displayed extraordinary growth and significant progress in the past few years. Each year the UAE hosts the largest healthcare exhibition in the region - the Arab Health. The Arab Health provides the perfect business platform for healthcare companies to showcase their products and enter into business relationships with health and medical institutions (Zaywa, 2012). During the 2014 event which was held in January over 3,000 exhibitors from 60 countries and more than 65,000 healthcare professionals worldwide showcased their latest medical and health care product (ibid).

Medical devices are controlled by the Ministry of Health which has provided certain guidelines for the registration of medical products. The guidelines are aimed to avoid ineffective and unsafe medical devices from entering the marketplace while providing the public with timely access to them. According to these, medical device manufacturers must register their products before they can market them in the UAE. There are a lot of medical device distributors in the UAE who face great challenges marked by an extremely competitive market place.

\section{Need for the Study}

There are many such companies like Al Zahrawi Medical in UAE that deal with the selling and distribution of medical equipment and pharmaceuticals. Some of these companies have been established since several decades ago while some others have recently come up. There is considerable competition between the various distributors to capture markets in the health care industry. The main focus of these companies would be to get large and small projects in private and government hospitals, clinics and laboratories. Optimizing the operations would help the company to achieve higher profits and have competitive advantage. Even if one process among the many processes involved in a supply chain does not perform well, it would affect the overall company performance.

\section{Industry Profile}

Al Zahrawi Group is a distributor in health care which was started in 1989 in Dubai specializing in Medical, Diagnostic Lab, Nuclear Medicine and Laboratory Equipments, and Analytical Lab supplies with presence throughout the GCC (UAE, KSA and Qatar)

\section{Methodology}

Based on the objectives stated in the introduction, questionnaire was considered to be the main instrument used for the collection of data. These questionnaires were distributed to the house members in the Procurement, Logistics and warehouse departments. The employees were interviewed face to face in order to obtain more relevant and comprehensive information and to ensure accuracy.

Direct observation was also made on the daily work procedures of the company to understand the conditions, problems that many employees may be unaware of or unable to describe adequately.

Primary data refers to that data that are collected to analyze a specific research problem at hand using procedures that fit the research problem the best. Primary data can be collected through questionnaires, telephone calls, emails, observation, etc.

The primary data for this research was collected using questionnaires by distributing them to respective departments, 11 major suppliers and 16 major customers. The secondary sources were the articles and other materials i.e. newspaper, internet and other publications, company's income statements, balance sheets and cash flow statements.

A study on supply chain management would be incomplete without the suppliers and the final customers. As the firm acts as the sole distributor in U.A.E for certain brands of medical/laboratory equipment questionnaires were prepared and sent by mail to the major suppliers. Questionnaires are also sent to some of the major revenue generating customers (hospitals) within the U.A.E.There was an informal discussion with the suppliers and customers when they were approached with questionnaires. 
SWOT \& Fish Bone analyses were done to arrive at a better conclusion on the study.

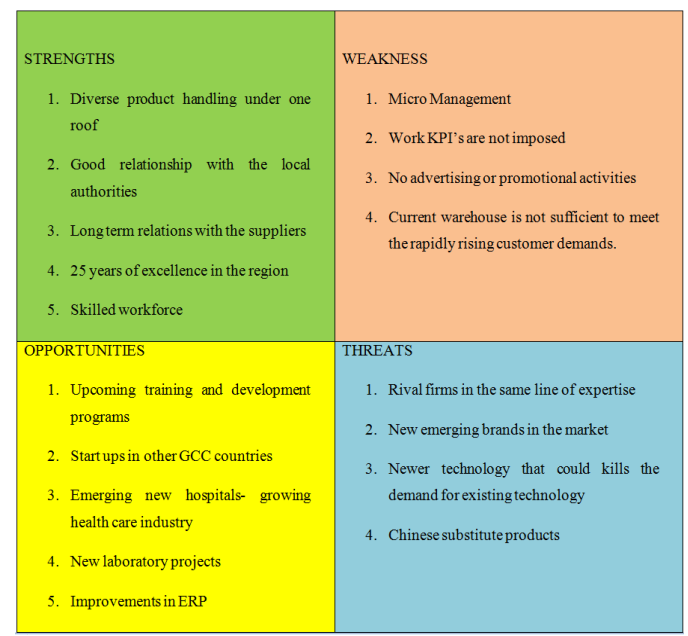

Fig 3. Shows the SWOT ANALYSIS

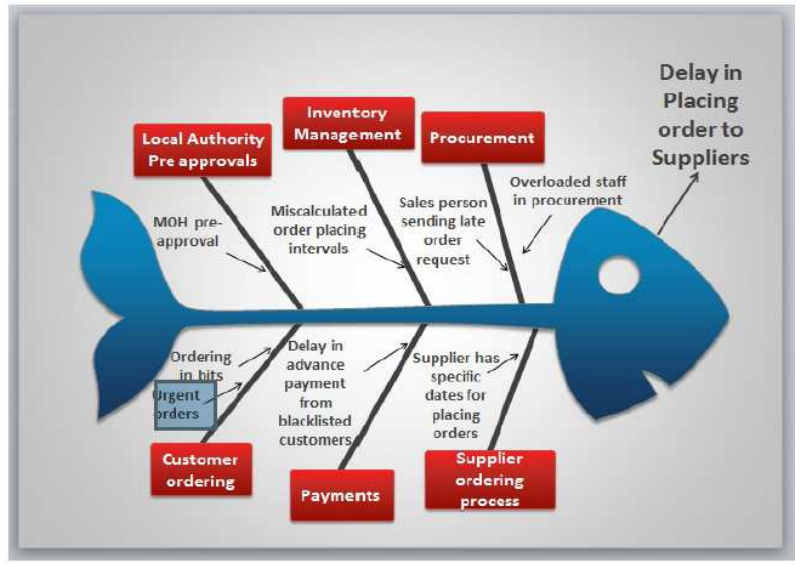

Fig 4. Shows the Fish Bone Diagram - Order Placement Delays

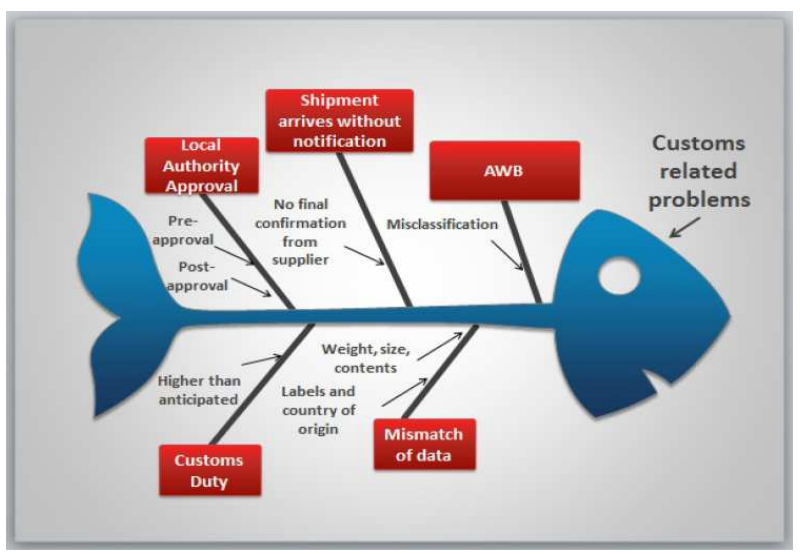

Fig 5. Shows the Fish Bone Diagram - Customs related problems

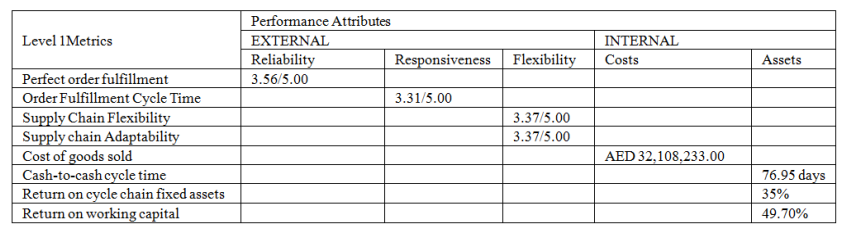

Fig 6. SCOR Performance Metrics
Flow Chart:

The proforma invoice is received form the supplier.L/C isn't being used for majority of the procurement based on the long term relationship with the fixed suppliers.(Al Zahrawi has completed 25 years in UAE).A purchase order is sent to the supplier and later on order confirmation is sent.

It is to be noted that each time a medical device/medical reagent/pharmaceutical needs to be procured. There should be prior approval from the ministry of health and final approval upon arrival of goods in the port on order to proceed for customs clearance.

It was found that many times, delay occurred waiting for pre-approval from $\mathrm{MOH}($ Ministry of health).MOH pre approvals usually take 5-6 working days. This pre-approved form needs to be submitted for post approval once the goods reach the port.only after obtaining the $\mathrm{MOH}$ post approval these medical items can be cleared from the port. $1 \%$ value is taken as $\mathrm{MOH}$ approval charges.

The following documents are required for customs clearance:

- Commercial invoice in which the exporter address to the importer stating total quantity of goods, the description of goods and the total value of individual items.

- Original certificate of origin issued by the chamber of commerce stating the origin of goods.

- $\quad$ Packing list stating the HS code of each item and the weight and packing method.

- Import permits(MOH approval for medical, FANR approval for nuclear, etc)

- $\quad$ Original Bill of Lading/Air way Bill

- Delivery order

Process duration:

- $\quad$ Pre-approval from local authority(5 days)

- $\quad$ Post approval from local authority(2 days)

- $\quad$ For air shipment(2-5 days from OK to forwarding)

- Online customs approval(within 24 hours)

- Customs inspection(within 2 hours)

- $\quad$ Local transportation(within 3 hours)

SWOT analysis is used in this research to know about the Industry.

The usage Questionnaire in this research is minimum as the research focuses on a particular model.

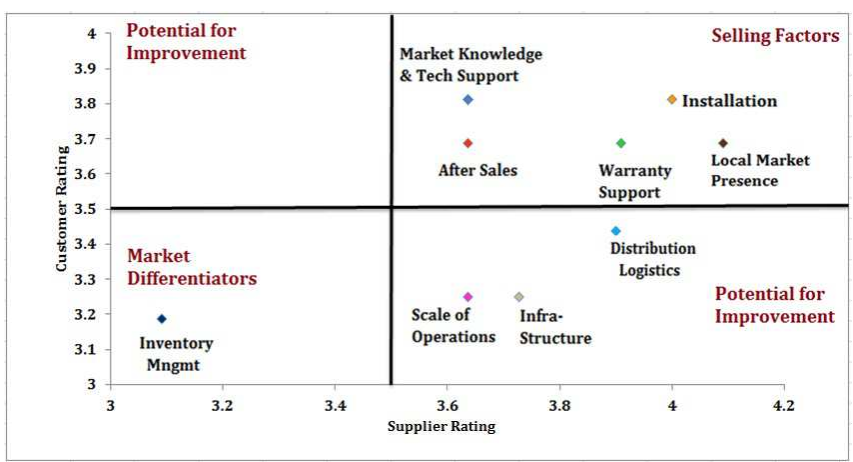

Matrix - Customer Rating VS. Supplier Rating 
Based on the above matrix created from the analysis of feedback from Suppliers and Customers through questionnaires, the following were observed:

Five factors namely Market knowledge \& Technical support, Installation, After-sales support,Warranty support, Local market presence have been rated high by both the Distributors and the clients. These may be termed as the Selling factors for the company. Maintaining them in this quadrant is imperative.

Distribution logistics, Scale of operations and infrastructure has been rated high by the distributors but the same have been rated low by Customers. One way to enhance the

Customer rating would be investigating the reasons of dissatisfaction by the Customers.

\section{Findings}

There is usually a delay of 5-6 days observed for preapprovals from $\mathrm{MOH}$ mainly due to improper/insufficient documentation.

Delays were observed some times for completing customs clearance of goods.

Delays were observed in placing orders to the suppliers

$\mathrm{L} / \mathrm{C}$ is not used with the suppliers dealt by Al Zahrawi, UAE. Over 25 years Al Zahrawi has secured trust and strong relationship with its suppliers and transactions are made on the basis of large credit limits granted from suppliers.

It was found that almost $95 \%$ of the suppliers dealing with Al Zahrawi, UAE use Ex-works as the preferred INCOTERM. Al Zahrawi uses international freight forwarders like FedEx, CEVA logistics, Expenditure International. Sometimes local freight forwarders like Inchcape Shipping Services are used in order to better negotiate power and manage costs.

Order forecasting was not given much of importance thus leading to inventory stock outs.

Customer demand is not often shared with the suppliers.

Lead times for delivery to customers were mentioned similar or almost similar to that of lead times from supplier. Lead time variability (LTV) was not carefully considered in some cases.

Inventory management techniques like $\mathrm{ABC}$ analysis or FSN analysis were not used. This resulted in poor inventory levels creating dissatisfaction among both customers and suppliers.

When the Day Sales Inventory (DSI) of certain business was calculated, it was found that Biochemistry, Gen. Laboratory, Imaging, Molecular Diagnostics and soft tissue Implants had DSI on the higher side. These divisions may have maintained its inventory quantities, but economic factors may have caused a drop in its sales, causing the DSI to increase dramatically. Or these divisions may have increased their inventory to generate more sales, but the sales did not increase and hence caused an increase in the number of inventory days.
It is observed that $\mathrm{Al}$ Zahrawi UAE enjoys a considerable long credit period (60-120 days) from most suppliers and it offers a shorter credit period (30-60days) to majority of it private customers. However the government customers are offered with 90 days credit period.

Majority of the suppliers follow a lead time of 4-8 weeks. Based on the specific supplier's lead time, Al Zahrawi, UAE ensures the delivery period to its customers. Penalties were paid by Al Zahrawi, UAE especially to government hospitals when orders were not fulfilled within the time promised. These penalties were charged on daily basis.

Al Zahrawi, UAE has to deal with the reverse logistics of radioactive dose containers returned from customer for disposal. It has to be ensured that the radioactive quantity in the dose container is below the specified limit of radiation. These containers have to be sent to the manufacturer for disposal through specialized containers.

The cash conversion cycle for the two years shows a decrease from 91.28 days in 2013 to 76.95 days in 2014, lower cash conversion cycle relates that a company can convert its products into cash through sales very quickly, and this is a very good position for the company to be in.

A return on assets and the return on working capital have considerably increased from the previous year. The return on asset has increased from $22.53 \%$ in 2013 to $35 \%$ in 2014 , and in the case of return on working capital it has increased from $44.40 \%$ in 2013 to $49.70 \%$ in 2014 . This increase implies that the company is using its working capital and its assets to the fullest extent possible; the company is being more efficient with its operation and handling its day-to-day working capital need effectively.

Five factors namely market knowledge and technical support, installation, after sales support, warranty support, local market presence have been rated high by both the distributors and the clients. These may be termed as the selling factors for the company. Maintaining them in this quadrant is imperative.

Distribution logistics, sale of operations and infrastructure has been rated high by the distributors but the same have been rated low by customers. One way to enhance the customer rating would be to investigate the reasons of dissatisfaction by the customers.

One factor which was identified by this survey for the company is inventory management. Low ratings for this parameter are a market differentiator distancing potential clients from the company. Inventory management should be carefully studied and measures should be taken to improve this condition.

The cash conversion cycle for the 2 years shows a decrease from 91.28 days in 2012 to 76.95 days in 2013, lower cash conversion cycle relates that a company can convert its products into cash through sales very quickly and this is very good position for the company to be in.

Majority of the suppliers have mentioned that urgent request from distributors affect the delivery of consignments that were just scheduled for shipment. It was informed that delay in sending out the previous order from the supplier 
warehouse often happens when such orders are made by the distributor. The entire consignment is held until the urgent order items are picked, packed, labeled and cleared from the system for shipment.

\section{Recommendations}

Managing inventory can be a daunting task, and if it is could not done properly it could cost the company thousands of dirham. There are several software solutions available for inventory management. Use inventory control techniques like $\mathrm{ABC}, \mathrm{FSN}$ and VED analysis as they are vital to the company's performance by helping to determine the importance of inventory items based on sales, usage or costs criteria. This method would help the company to give different levels of inventory control to different SKUs based on their relative importance.

As the Day Sales Inventory OF Biochemistry, Gen. Laboratory, Imaging, Molecular Diagnostics and Soft Tissue Implants divisions were high, special care must be taken not to overstock items in these departments. Also, the concerned sales executives must ensure the inventory is cleared in shorter intervals than the current scenario.

Knowing the changing trends in the healthcare industry, efforts should be made to control the costs without affecting patient care and safety. In order for the healthcare supply chain or for that matter any supply chain to be effective, information has to be shared between manufacturers and distributors. Customers demand has to be shared with the suppliers.

Even though Ex-works (EXW) is the preferred choice for most suppliers, companies Al Zahrawi can have a full control of the landing costs by carefully selecting freight forwarders by considering several factors like pricing, reliability, tracking facility, flexibility etc. Better negotiation with freight forwarders can considerably help decrease the costs.

Lead time variability (LTV) has to be considered as an important factor when setting up delivery time to customers. In this way the variability in lead time from the suppliers due to stock outs, public holidays etc. can be covered up. By doing so Al Zahrawi, UAE can achieve shorter lead times and would be able to match the supply and demand in a better way.

A warehouse management system (WMS) is vital to improve the efficiency of a company's warehouse operations from inventory control, shipping and receiving, to order fulfillment. Advanced WMS have come with features like RFID, mobile computers, wireless networks and voice picking applications. WMS will help streamline multiple warehouse functions like receiving put away, picking, packing and shipping.

All the factors affecting the forecasting should be looked into and checked if they still influence the demand forecast. Improved forecasts can benefit all trading partners in the supply chain. It can result in lower inventory levels, reduced stock outs and higher customer satisfaction.

Al Zahrawi has to consider 3PL providers to take care of reverse logistics of radioactive dose containers returned from customer for disposal.

\section{Conclusions}

This article is the first step to analyze the efficiency in healthcare supply chain at Al Zahrawi and discussed the collaborative practices currently in place. In an epoch where many healthcare systems are under major critique, understanding the complexity of the system is the first step towards improvement. This study provided empirical insights, in terms of health care complexity and identified significant differences in terms of product portfolio range, cost contribution, delivery frequency patterns, size of supplier base, lead time, inventory management and distribution tactics and replenishment control and decision. The findings suggested that optimizing the operations would help the company to achieve higher profits and have a competitive advantage.

\section{References}

[1] Kauffman .G. Ralph 1 (No date), "How to achieve cost savings from supply chain management: Techniques that work",

http://www.ism.ws/files/Pubs/Proceedings/CrimiGG.pdf, retrieved on 13 May, 2014. 1Associate professor of Management, Emeritus

[2] Walter, D. \& Rainbird, R. (2007) 1, "Strategic Operations Management: A value chain approach", New York: Palgrave Macmillan. 1Consultants, Supply chain management.

[3] Medina. A. Lourdes \& Santana Marlyn (2014) 1, "A Review of the Supply Chain Peculiarities for Medical Products", Proceedings of the 2014 Industrial and Systems Engineering Research Conference, pp.1-10.

[4] Global Healthcare Exchange (2011), “ A Look inside your customers world" Medical device supply chain council, www.medsupplychain.org/pdfs/GHXConway.pdf , retrieved on 2, April,, 2013. 1Medical device supply chain council

[5] Smith, B. K., Nachtmann, H1., and Pohl, E. A1., (2012), "Improving healthcare supply chain processes via data standardization", Engineering Management Journal, Vol. 24, No.1, pp. 3-10. 1Assistant Professor of Industrial Engineering, University of Arkansas. 2Assistant Professor of Industrial Engineering, University of Arkansas.

[6] José Ceronil and Rodrigo Alfaro (2011). Information Gathering and Classification for Collaborative Logistics Decision Making, Supply Chain Management - New Perspectives, Prof. Sanda Renko (Ed), http://www.intechopen.com/books/supply-chain-managementnewperspectives/ information-gathering-and-classificationfor-collaborative-logistics-decision-making, pp.257-274. 1School of Industrial Engineering, Chile. 2Professor, Pontificia Universidad Católica de Valparaíso.

[7] Li Ling, Su Qin and Chen Xu (2010) 1, "Ensuring supply chain quality performance through applying the SCOR model", Vol.49, Issue 1, pp. 33-57. 1Supply chain consultants. 
[8] Jerry (alias )Mathew (2014) 1, “ Analysis on the supply chain and designing the supply chain operations reference (SCOR)Performance Metrics of Al Zahrawi Medical, UAE, Master of Business Administration Thesis, Manipal University, Dubai, pp. 1-85. 1Research Scholar, Manipal University, Dubai.
[9] Ryder Jane (2013)1, "Medical Device Industry Profile 2013", https://www.ic.gc.ca/eic/site/lsgpdsv.nsf/eng/h_hn01736.html, retrieved on 26, April, 2014. 1President, Clinical services, USA.

[10] Zaywa (2012), "Guidelines for Medical Devices in the UAE March2013. 1UAE Business and financial news. 